\title{
Bias in CMIP6 models as compared to observed regional dimming and brightening
}

\author{
Kine Onsum Moseid ${ }^{1}$, Michael Schulz ${ }^{1,2}$, Trude Storelvmo ${ }^{2}$, Ingeborg Rian Julsrud ${ }^{2,1}$, Dirk Olivié ${ }^{1}$ Pierre Nabat $^{3}$, \\ Martin Wild ${ }^{4}$, Jason N. S. Cole ${ }^{5}$, Toshihiko Takemura ${ }^{6}$, Naga Oshima ${ }^{7}$, Susanne E. Bauer ${ }^{8}$, and Guillaume Gastineau ${ }^{9}$ \\ ${ }^{1}$ Norwegian Meteorological Institute, Research Department, Oslo, Norway \\ ${ }^{2}$ University of Oslo,Department of Geosciences, Section for Meteorology and Oceanography, Oslo, Norway \\ ${ }^{3}$ Centre National de Recherches Meteorologiques (CNRM), Universite de Toulouse, Météo-France, CNRS, Toulouse, France \\ ${ }^{4}$ Institute for Atmospheric and Climate Science, Swiss Federal Institute of Technology (ETH), Zurich, Switzerland \\ ${ }^{5}$ Canadian Centre for Climate Modelling and Analysis, Environment Canada, Victoria, British Columbia, Canada \\ ${ }^{6}$ Climate Change Science Section, Research Institute for Applied Mechanics, Kyushu University, Fukuoka, Japan \\ ${ }^{7}$ Meteorological Research Institute, Japan Meteorological Agency, Tsukuba, Ibaraki, Japan \\ ${ }^{8}$ Center for Climate Systems Research, Columbia University, NASA Goddard Institute for Space Studies, \\ New York, NY, USA \\ ${ }^{9}$ LOCEAN, IPSL, Sorbonne Université, IRD, MNHN, CNRS, Paris, France
}

Correspondence: Kine Onsum Moseid (kristineom@met.no)

Received: 30 December 2019 - Discussion started: 4 February 2020

Revised: 9 November 2020 - Accepted: 9 November 2020 - Published: 22 December 2020

\begin{abstract}
Anthropogenic aerosol emissions have increased considerably over the last century, but climate effects and quantification of the emissions are highly uncertain as one goes back in time. This uncertainty is partly due to a lack of observations in the pre-satellite era, making the observations we do have before 1990 additionally valuable. Aerosols suspended in the atmosphere scatter and absorb incoming solar radiation and thereby alter the Earth's surface energy balance. Previous studies show that Earth system models (ESMs) do not adequately represent surface energy fluxes over the historical era. We investigated global and regional aerosol effects over the time period 1961-2014 by looking at surface downwelling shortwave radiation (SDSR). We used observations from ground stations as well as multiple experiments from eight ESMs participating in the Coupled Model Intercomparison Project Version 6 (CMIP6). Our results show that this subset of models reproduces the observed transient SDSR well in Europe but poorly in China. We suggest that this may be attributed to missing emissions of sulfur dioxide in China, sulfur dioxide being a precursor to sulfate, which is a highly reflective aerosol and responsible for more reflective clouds. The emissions of sulfur dioxide used in the models do not show a temporal pattern that
\end{abstract}

could explain observed SDSR evolution over China. The results from various aerosol emission perturbation experiments from DAMIP, RFMIP and AerChemMIP show that only simulations containing anthropogenic aerosol emissions show dimming, even if the dimming is underestimated. Simulated clear-sky and all-sky SDSR do not differ greatly, suggesting that cloud cover changes are not a dominant cause of the biased SDSR evolution in the simulations. Therefore we suggest that the discrepancy between modeled and observed SDSR evolution is partly caused by erroneous aerosol and aerosol precursor emission inventories. This is an important finding as it may help interpret whether ESMs reproduce the historical climate evolution for the right or wrong reason.

\section{Introduction}

Aerosol particles scatter and absorb radiation and change the radiative properties of clouds, thereby altering Earth's energy balance (Boucher et al., 2013). Anthropogenic aerosol emissions have substantially increased over the last century, but the quantification of the effect has been characterized by large uncertainties. Earth system models (ESMs) are evalu- 
ated based on their ability to reproduce the climate evolution of the past 165 years, and the sparsity of aerosol-related observations in the pre-satellite era plays a dominant role in the uncertainty connected to these historical experiments. An improved understanding of the historical aerosol effect would increase the accuracy and credibility of ESM future climate projections.

Aerosol particles cause changes in the amount of sunlight reaching the surface together with changes in insolation, cloud cover, water vapor and other radiatively active gases (Wild et al., 2018). Extraterrestrial influences like the 11year cycle of the Sun have not created any important trends on decadal timescales in Earth's surface solar radiation in the past century (Eddy et al., 1982; Wild, 2009). Water vapor amount has not changed sufficiently in recent decades to have an effect on decadal fluctuations of incoming sunlight at the surface (Wild, 2009; Wang and Yang, 2014; Yang et al., 2019; Hoyt and Schatten, 1993; Ramanathan and Vogelmann, 1997; Solomon et al., 2010), and radiatively active gases dominate in the longwave spectrum (Ramanathan et al., 1989).

The relative roles of clouds, aerosols and their interactions in historical variations of surface downwelling shortwave radiation (SDSR) are still disputed, but previous studies have found that aerosol effects dominate on multidecadal timescales, while cloud effects are relevant on shorter timescales (Wild, 2016; Romanou et al., 2007). Aerosol effects can be divided into the direct and indirect effects. The direct effect is the scatter or absorption directly caused by a dry aerosol, also called the aerosol-radiation interaction (ari) (Boucher et al., 2013), and the indirect effect is how aerosols change properties in clouds, also called aerosol-cloud interactions (aci). Aci includes both a change in cloud lifetime and most importantly a change in cloud albedo, making the cloud appear brighter (Boucher et al., 2013).

Assuming aerosol effects dominate the multidecadal timescales, SDSR can serve as a proxy for aerosol effects. The Global Energy Balance Archive (GEBA) dataset contains measurements of SDSR as far back as in 1922 (Wild et al., 2017) and as such represents a unique and valuable dataset for evaluation of simulated aerosol effects prior to the satellite era.

Observed SDSR from the GEBA dataset reveals a widespread negative trend from the 1950s to the late 1980s, commonly referred to as "global dimming" (Liepert, 2002; Wild, 2016). The magnitude of this dimming differs vastly between regions, which is expected if the cause of dimming were regionally different increases in aerosol emissions, as has been proposed by Wild et al. (2007), Sanchez-Romero et al. (2014), and Wild (2016). In some areas a positive trend in SDSR follows the dimming, and this SDSR increase has been termed "brightening" (Wild et al., 2005). Brightening is connected to the reduction in anthropogenic aerosol emission (Nabat et al., 2014). Fewer particles suspended in the air allow for more sunlight to reach the surface and thus an in- crease in the measured SDSR. Previous studies show that historical simulations from ESMs do not reproduce the observed global transient development of SDSR (Storelvmo et al., 2018; Wild, 2009; Allen et al., 2013; Wild and Schmucki, 2011). The cause of this discrepancy is not known but may be connected to uncertainties in aerosol emission inventories of the past, or, as Storelvmo et al. (2018) suggested, other uncertainties concern how models treat processes that translate aerosol emissions into radiative forcing.

In this study we use gap-filled data based on the GEBA dataset, together with several recent CMIP6 historical model experiments from eight climate models to investigate the aerosol effect in the time period 1961-2014, globally and regionally. In the middle of this time period (around the late 1990s), the main region of high anthropogenic aerosol emissions shifted from Europe and North America to Asia. We have chosen to focus on the regions of Europe and Asia in this study, as the models exhibit diverging abilities to reproduce the observed SDSR in these regions. We also use observational cloud cover data to briefly assess the role of cloud cover in the historical development of SDSR. We explore the relation between regional SDSR and aerosol emissions using a set of ESM experiments with differing aerosol emissions; some have pre-industrial aerosol emissions, while others use the most recent and best available historical aerosol emission inventory (Hoesly et al., 2018). This paper thereby provides new insights into the question of whether state-ofthe-art ESMs can adequately reproduce a part of the changes in the surface energy budget over the historical era. This is in turn an important indication of whether the ESMs reproduce the dominant processes governing the historical climate evolution.

The paper is structured as follows. In Sect. 2 we begin by presenting the two observational datasets used, followed by a detailed description of the experiments simulated by the eight models chosen to be part of this study. The methods used to obtain and analyze the data finalize Sect. 2. The results are presented in Sect. 3, starting with a global view of dimming and brightening before focusing on regional assessments of SDSR, clear-sky SDSR, and cloud cover. Section 4 discusses the implications of our results and how they compare to previous studies, before final conclusions are presented in Sect. 5.

\section{Data and methods}

\subsection{Observations}

The GEBA holds data from ground-based stations measuring energy fluxes at the Earth's surface around the globe (Wild et al., 2017). Pyranometers were used in most of the measurement sites, which have an accuracy limitation of $3 \%-$ $5 \%$ of the full signal (Michalsky et al., 1999; Wild et al., 2013). We use the monthly mean data from 1487 stations 
in the time period 1961-2014 measuring downwelling shortwave radiation. The GEBA dataset has been complemented by a machine learning technique (random forests, Breiman, 2001) as explained in Storelvmo et al. (2018) to cover time periods of missing observations in the measurements and facilitate comparison to the gridded model data. This allows for all 1487 stations to have data on each time step, so that all regions have a complete record and the same number of stations throughout the entire time period in question.

Monthly mean cloud cover data are provided by the Climatic Research Unit (University of East Anglia) and NCAS, and we are using version 4.02 of this dataset (CRU). CRU covers the period 1901-2017 (Harris et al., 2020) and consists of a climatology made from measurements at meteorological stations around the globe, interpolated to a $0.5^{\circ}$ latitude-longitude resolution grid covering continental areas. Information on interpolation methods and procedures used to create the gridded dataset is given in Harris et al. (2020) and references therein. In short, CRU has its foundation in station data but is interpolated to a grid using angular-distance weighting. The cloud cover variable is largely derived as a secondary variable, based on measurements of other parameters such as sunshine hours and diurnal temperature range.

\subsection{Models and CMIP6}

Eight climate models (NorESM2, CanESM5, MIROC6, CESM2, CNRM-ESM2-1, GISS-E2-1-G, IPSL-CM6A-LR, MRI-ESM2-0) were chosen for this study, based on available data and their involvement in relevant model intercomparison projects within the Coupled Model Intercomparison Project Phase 6 (CMIP6) (Eyring et al., 2016). As this study focuses on dimming and brightening, we have chosen experiments from model intercomparison projects (MIPs) that include perturbed historical simulations with which one can single out the effect of anthropogenic aerosol emissions in our diagnostic variables. An overview of models and experiments can be found in Table 1. This section will give a more detailed description of the experiments in Table 1 and explain why they were chosen.

Every model that takes part in CMIP6 has to deliver a set of common experiments; among these is the historical simulation. As can be seen in Table 1, all the models have provided historical simulation results. All other experiments listed in Table 1 are simulations covering the historical period (1850-2014) but with specific alterations dependent on what model intercomparison project they are a part of.

The Detection and Attribution Model Intercomparison Project (DAMIP) has the goal of improving estimations of the climate response to individual forcings (Gillett et al., 2016) and includes three relevant experiments. One experiment traces exclusively the impact of anthropogenically emitted aerosols as forcing agents over the historical period and is called hist-aer. This means no anthropogenic greenhouse gas emissions or natural climate forcings are used in this simulation. The hist-nat experiment consists of only the perturbations due to the evolution of the natural forcing, e.g., from stratospheric aerosols of volcanic origin and solar irradiance variations. Finally, the hist-GHG experiment has only forcings from changes in the well-mixed greenhouse gases. These experiments were chosen as they give a unique insight into how a fully coupled climate model attributes responses over the historical period to the different climate forcings.

While DAMIP provides a good framework for one of the main questions in CMIP6, namely how the Earth system responds to forcing, RFMIP, the Radiative Forcing Model Intercomparison Project, focuses on understanding the forcing itself. RFMIP contains a large set of experiments to further understand the radiative forcing of the past and the present (Pincus et al., 2016). We use two experiments from RFMIP, both with sea surface temperatures prescribed to pre-industrial values. One experiment includes both anthropogenic and natural aerosol emissions (piClim-histall), while the other only includes anthropogenic aerosol emissions (piClim-histaer). When sea surface temperatures are kept to pre-industrial values, the global surface temperature development stalls, and the simulation will keep to first order a preindustrial climate. Sea surface temperatures changes would have an effect on cloud cover, which in turn can affect SDSR. These piClim experiments will show the direct atmospheric forcing on SDSR due to greenhouse gases and aerosols, alone or in combination, without including cloud cover changes induced by global warming.

The third MIP included in this study is the Aerosol Chemistry Model Intercomparison Project (AerChemMIP), which is designed to answer questions regarding the specific effect of aerosols and other near-term climate forcers (NTCF) on climate. NTCFs include methane, tropospheric ozone, aerosols and their precursors (Collins et al., 2017). Three experiments have been selected from AerChemMIP, histSST, with all forcing agents included, and two perturbations which have pre-industrial aerosol emissions: hist-piAer and histpiNTCF. The hist-piNTCF experiment has in addition preindustrial NTCF levels for ozone. A difference in these two simulations would only appear if ozone concentrations were computed in an interactive chemistry scheme. These two simulations are coupled and are comparable to the historical experiment. The experiment histSST uses all forcing agents and the sea surface temperatures derived from the historical simulation so that the temperature evolution, and hence its effect on SDSR, should be similar to the historical experiment but removes responses involving a coupled ocean. These experiments together with the historical experiment were chosen to differentiate between historical changes in aerosol and tropospheric ozone or whether a mixing layer in the ocean may have had an effect on dimming.

Data from all experiment ensembles from each of the MIPs listed above provide useful information on the role of anthropogenic aerosol emission in dimming and/or brightening. 
Table 1. Model participation, as used in this study, in CMIP6 model intercomparison projects (MIPs) and their experiments.

\begin{tabular}{|c|c|c|c|c|c|c|c|c|}
\hline Experiment & NorESM2 & CanESM5 & MIROC6 & CESM2 & CNRM-ESM2-1 & GISS-E2-1-G & IPSL-CM6A-LR & MRI-ESM2-0 \\
\hline historical & $\mathrm{x}$ & $\mathrm{x}$ & $\mathrm{x}$ & $\mathrm{x}$ & $\mathrm{x}$ & $\mathrm{x}$ & $\mathrm{x}$ & $\mathrm{x}$ \\
\hline hist-aer & $\mathrm{x}$ & $\mathrm{x}$ & $\mathrm{x}$ & & & $\mathrm{x}$ & $\mathrm{x}$ & $\mathrm{x}$ \\
\hline hist-GHG & $\mathrm{x}$ & $\mathrm{x}$ & $\mathrm{x}$ & $\mathrm{x}$ & & $\mathrm{x}$ & $\mathrm{x}$ & $\mathrm{x}$ \\
\hline hist-nat & $\mathrm{x}$ & $\mathrm{x}$ & & $\mathrm{x}$ & & $\mathrm{x}$ & $\mathrm{x}$ & $\mathrm{x}$ \\
\hline piClim-histaer & $\mathrm{x}$ & $\mathrm{x}$ & $\mathrm{x}$ & & & $\mathrm{x}$ & & \\
\hline piClim-histall & $\mathrm{x}$ & $\mathrm{x}$ & $\mathrm{x}$ & & & $\mathrm{x}$ & $\mathrm{x}$ & \\
\hline hist-piAer & $\mathrm{x}$ & & $\mathrm{x}$ & & & & & $\mathrm{x}$ \\
\hline hist-piNTCF & $\mathrm{x}$ & & $\mathrm{x}$ & & $\mathrm{x}$ & & & $\mathrm{x}$ \\
\hline histSST & $\mathrm{x}$ & & $\mathrm{x}$ & & $\mathrm{x}$ & & & $\mathrm{x}$ \\
\hline
\end{tabular}

\subsection{Methods}

The GEBA stations have been divided into regions based on the country and continent. The number of stations in a region is presented together with the first results in the caption of Fig. 2. The number of stations per region remains constant throughout the time period because of our gap-filling approach. A figure with the spatial distributions and trend of SDSR per station in GEBA used in this study is found in Fig. 1 in Storelvmo et al. (2018).

All model output and CRU results have been co-located to GEBA station locations using the nearest neighbor method. This entails that if two GEBA stations are within one grid box of a model, data from that grid box will be retrieved twice by nearest neighbor interpolation, as every station has been weighted equally. A global mean is defined here as the mean of a variable across all GEBA station locations. A regional mean is a mean of a variable across the GEBA station locations registered to that same region in the GEBA data. When a result is shown as an anomaly, as opposed to an absolute value, the general formula has been to subtract the baseline value, defined as the mean of the first 5 years of the investigated time period (1961-2014), from the time series in question. To clarify - first an average value per year per region is calculated, and then a new mean is created from the first 5 years of this time series. This 5-year mean is then subtracted from each year in the time series for the region in question and presented as an anomaly. We will often present data as 6 -year averages, as yearly variabilities are not the focus of this study. These 6-year averages are simply made by dividing the time series over 54 years (1961-2014) into nine equal intervals and averaging these intervals together. When the atmospheric burdens of $\mathrm{SO}_{4}$ are shown together with observed SDSR from GEBA, the time series have been smoothed using a 10-year running mean, and this is the only data in the paper shown using this smoothing technique.

The "baseline" values for global SDSR and cloud cover in the models and observations of this study can be found in the Appendix in Table A1.
The model data have been retrieved from the Earth System Grid Federation (ESGF) (Cinquini et al., 2014). ESGF is a data management system consisting of multiple geographically distributed nodes that coordinate through a peer-to-peer (P2P) protocol (Fan et al., 2015). We have used three ensemble members for the historical experiment to present internal variability in the models and one ensemble member from the rest of the experiments shown, as not every experiment had requested more than one simulation. Table A2 in the Appendix shows the resolutions, aerosol schemes, and aerosol complexity of the models in this study, and Sect. A2 explains the variables and variant labels downloaded.

\section{Results}

\subsection{Model variability}

Figure 1 shows the SDSR anomaly for each model of the study co-located to all GEBA stations, 1487 in total as compared to the observed SDSR anomaly. The aerosol effective radiative forcing (aerosol ERF) corresponding to each model is obtained from Smith et al. (2020) and is listed in each panel to illustrate the strength of the aerosol radiative effect in the model.

Each climate model has its own internal variability and thereby represents its separate climate systems. SDSR is a highly variable metric on a year-to-year basis, which can be seen both in the GEBA data in black in Fig. 1 and in following a single ensemble member per model. Within each model ensemble one can see that no member is equal to another, which is a clear signal of the internal variability of each model. The spread of all three ensemble members in a 6-year period can be read from the height (interquartile range) of the boxes in the 6-year intervals; note that this spread is dominated by large inter-annual variabilities within each member. One example is GISS-E2-1-G, where each ensemble member has large interannual variabilities: the boxes present long whiskers and large interquartile ranges, but when comparing the ensemble member 6-year means one by one they mostly 

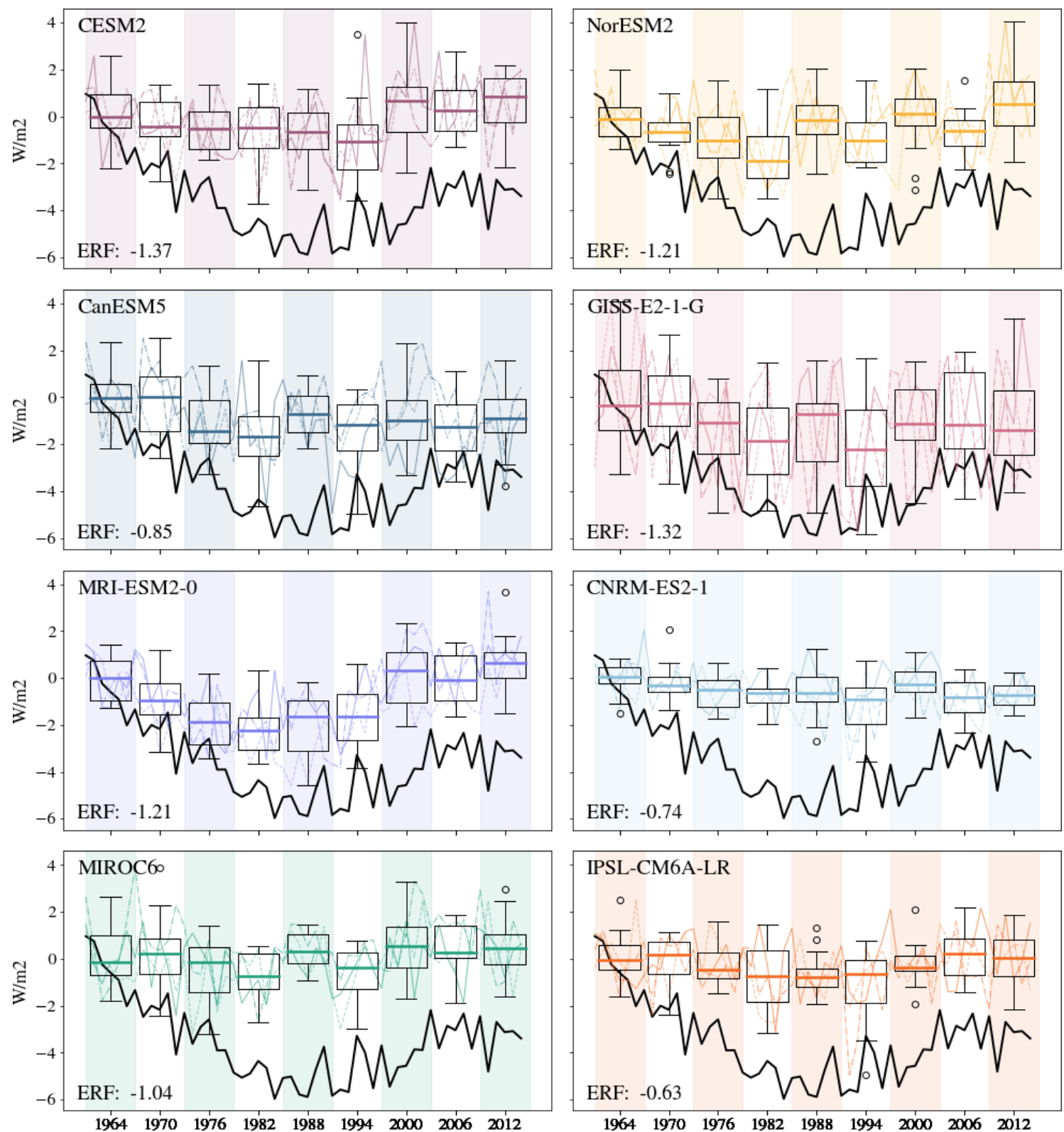

Figure 1. Global surface downwelling shortwave radiation (SDSR) anomaly at the surface for GEBA (black) and three ensemble members for the historical simulation of the eight models in this study. The boxes are made for 6-year intervals (shaded in background) based on 6-yearly means and three ensemble members per model. Colored lines behind boxes show yearly values of SDSR anomaly per ensemble member. The height of each box represents the interquartile range of the data, and the thick colored line within each box is the median. The whiskers show the minimum and maximum values of the selection of data, and the outliers are shown as a hollow dot. Results are co-located to all GEBA stations (1487) throughout the time period. The aerosol ERF as found in Smith et al. (2020) per model is shown in the bottom left of each panel.

agree on their magnitudes of SDSR anomaly, so the intraensemble spread is not large for GISS-E2-1-G. We find (not shown here) that the model with the least interannual variabilities is CNRM-ES2-1, while the model with the largest inter-ensemble disagreements is CanESM5.

Figure 1 also shows that the models in general do not agree with the observed global SDSR anomaly shown in black.
Dimming and brightening are tendencies in surface radiation that are observed on longer than interannual timescales; with this in mind, SDSR from models will in general be presented as 6-year means for the remainder of this paper. The model MRI-ESM2-0 shows the most similar SDSR evolution compared to the observed data according to Fig. 1. 
The model with the strongest aerosol ERF is CESM2, while the weakest aerosol ERF is presented by IPSL-CM6ALR.

\subsection{Dimming and brightening}

The change in SDSR in the historical simulations from the eight models is presented together with GEBA data in Fig. 2. Panel (a) of this figure corresponds to the results shown in Fig. 1. Each model graph in Fig. 2 represents the ensemble mean of the model in question averaged over 6 years, based on three ensemble members. GEBA data are shown in black, also as 6-year averages, but with the yearly time series shown in grey in the background. Model simulations show small changes in global SDSR compared to observations (Fig. 2a). Global SDSR is observed to decrease over the 1487 stations until the late 1980s before increasing again, clearly showing the global "dimming" and "brightening" as found in previous studies listed in the introduction.

None of the models outperform one another globally, and there is a discrepancy of about $2-3 \mathrm{~W} \mathrm{~m}^{-2}$ between models and observations. To further identify from where this discrepancy originates, we consider some geographical regions separately. Asia and Europe are relevant regions in regards to anthropogenic aerosol emissions (as explained in Sect. 1) and thereby also relevant to global dimming and brightening. The historical SDSR evolutions in Europe and Asia are presented in Fig. 2b and c, respectively. European SDSR is relatively well represented by the model simulations. The yearly GEBA time series has values within the shaded area that shows the standard deviation of the total of 24 model ensemble values in almost every 6-year period in Europe. The dimming in Europe is believed to have started before 1961 (Wild, 2009), which partly explains why the initial European dimming in Fig. $2 b$ is weak. GEBA shows a short-term positive anomaly between 1970 and 1980, which is not caught by the models. This peak is currently unexplained, but a short assessment of its possible association with changes in cloud cover is found in Sect. A1 in the Appendix.

There is generally a large discrepancy between model simulations and observations of SDSR in Asia, as seen in Fig. 2c. The ground stations in Asia show a noticeable trend change in SDSR in the transition from the 1980s to 1990s that is not apparent in the model simulations. The historical model simulations show a consistent negative trend during the entire historical period in question in Asia. Historically, countries with relatively high emissions in Asia include India, Japan, and China (Hoesly et al., 2018), and the SDSR evolution for each of these countries is shown in Fig. 2d, e, and f, respectively.

Figure $2 \mathrm{~d}$ shows that the models capture a relatively strong negative trend of SDSR in India, with MIROC6 being the model with the most modest trend. There are evident differences between observations and simulations in both Japan and China. Ground stations in Japan show a sharp decrease in SDSR until the early 1970s followed by some variations until a new minimum value is reached around 1990 before an increase in SDSR is measured. The minimum value around 1990 and the following positive trend is similar to that of China. Japan is downwind of the Asian continent and thus believed to be influenced by aerosol emissions from China. Model simulations do not capture the magnitude of dimming in Japan or the apparent brightening in the 1990s. The timing of minimum SDSR occurs differently in models, which was also seen in Fig. 2a.

Observations from China (Fig. 2f) show a trend change in SDSR similar to the one identified in Fig. 2c for Asia as a whole, with the minimum value found in 1989 . We note that China consists of 119 GEBA stations, while Asia as a whole consists of 311 stations; thus, the Asian average is largely impacted by SDSR as measured in Chinese stations. In general the historical model simulations show dimming throughout the historical period in China, meaning none of them shows a similar trend change to the one from the observational dataset. This post-1990 trend change is a source of discussion within the field, and a thorough assessment, relevant to the conclusions from this study, is found in Sect. 4.1.

\subsection{Dimming and brightening over China in various CMIP6 experiments}

In order to understand which forcing agents are responsible for the overall trends in SDSR in the models, we now investigate China for the experiments listed in Table 1. Figure 3a shows perturbed historical simulations as performed in DAMIP together with observations of SDSR. DAMIP has two experiments without historical anthropogenic aerosol emission (dashed/hist-nat and stippled/hist-GHG lines) and one experiment with historical anthropogenic aerosol emissions (solid lines/hist-aer). The experiment hist-aer is the only experiment in DAMIP exhibiting a distinguishable dimming signal. SDSR from hist-aer shows patterns similar to the historical simulations with continuous dimming throughout the period, unlike the observed SDSR. SDSR in the experiments hist-nat and hist-GHG do not show signs of dimming or brightening over the investigated period in China, which confirms that water vapor or stratospheric aerosols are not the dominant cause of multidecadal dimming signals in the fully coupled historical model simulations. This is supported by previous work, as mentioned in the introduction.

Out of the three experiments from AerChemMIP only, histSST, has prescribed sea surface temperatures and contains changes in anthropogenic aerosol emissions. This is consistent with the time evolution of SDSR in histSST as the simulations diverge from the other simulations as time progresses (Fig. 3b). Keeping in mind that histSST also has anthropogenic greenhouse gas (GHG) emissions in addition to natural forcers, the only difference from histSST to the historical experiment is the absence of a coupled ocean and the use of prescribed sea surface temperatures. The model MRI- 


$\begin{array}{ll}\rightarrow \text { GEBA } & \text { - GISS-E2-1-G } \\ - \text { GEBA (yearly) } & -4 \text { MRI-ESM2-0 } \\ - \text { CESM2 } & - \text { CNRM-ES2-1 } \\ - \text { NorESM2 } & \rightarrow \text { MIROC6 } \\ \rightarrow \text { CanESM5 } & \rightarrow \text { IPSL-CM6A-LR }\end{array}$
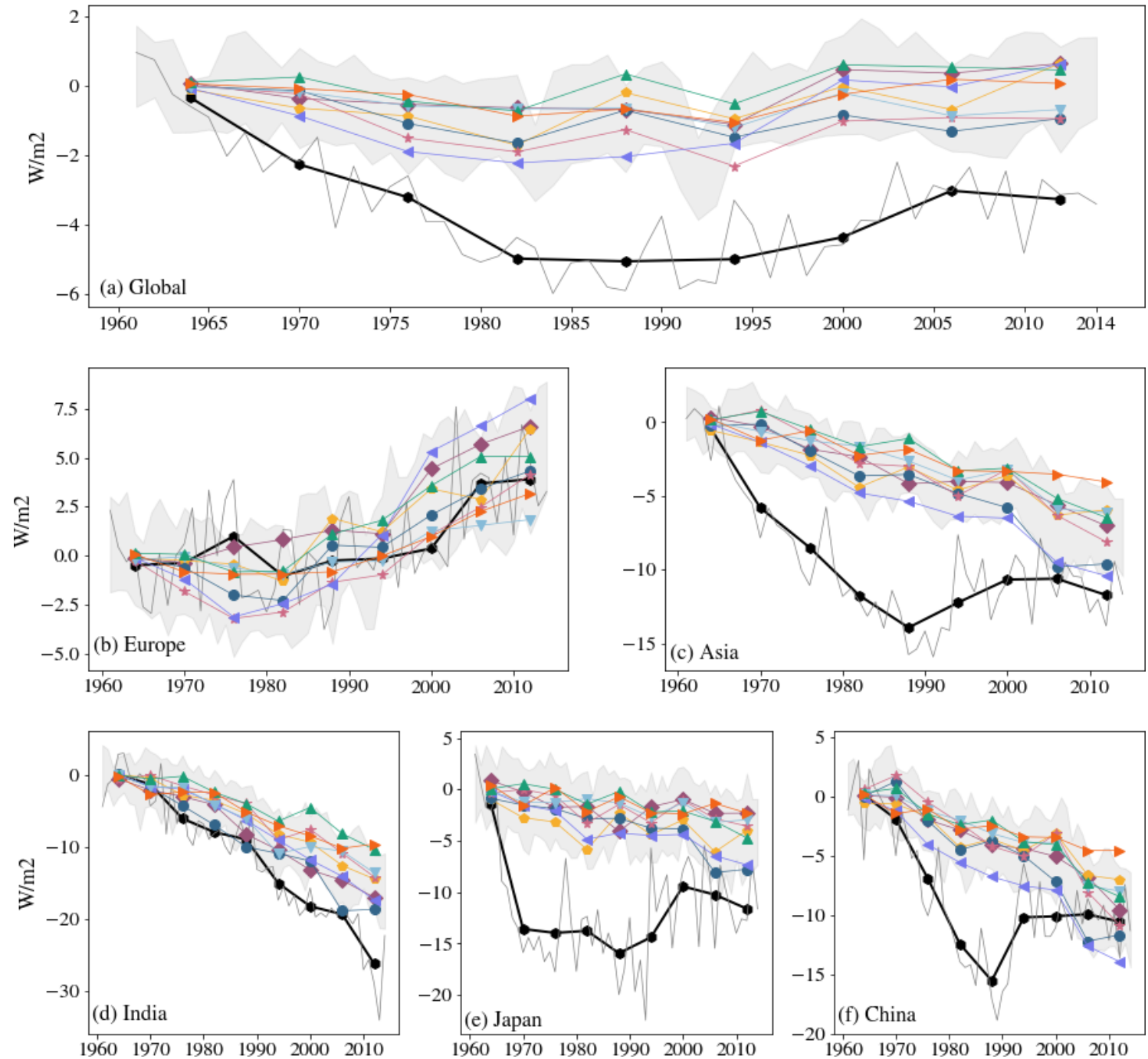

Figure 2. Six-year averages of the SDSR anomaly at the surface for GEBA and eight Earth system models. Results are co-located at (a) all GEBA stations (1487), (b) European (503), (c) Asian (311), (d) Indian (15), (e) Japanese (100), and (f) Chinese (119) stations. Numbers in parentheses are the number of ground stations in the respective region. The entire 54-year period has been divided into intervals of 6 years and then averaged together to make nine data points as shown by the markers. The grey shading represents 1 standard deviation from the yearly total ensemble mean.

ESM2-0 presents the strongest dimming in both DAMIP and AerChemMIP. The simulations with pre-industrial aerosols (hist-piAer) and pre-industial near-term climate forcers, including aerosols and ozone (hist-piNTCF), show very small or negligible changes in the SDSR over the time period considered.

Recall that the experiments of RFMIP utilize preindustrial SSTs, meaning essentially there is no global warming in these experiments. In the RFMIP experiments shown in Fig. 3c both piClim-histaer and piClim-histall con- tain anthropogenic aerosol emissions, and all simulations show a continuous dimming throughout the period. There is no clear distinction between experiments containing GHG emissions in addition to anthropogenic aerosol emissions (solid lines/piClim-histall) and the experiments only containing anthropogenic aerosol emissions (stippled lines/piClimhistaer). This implies that greenhouse gases without their global warming effect do not affect multidecadal all-sky SDSR in a significant way over China throughout the period, 

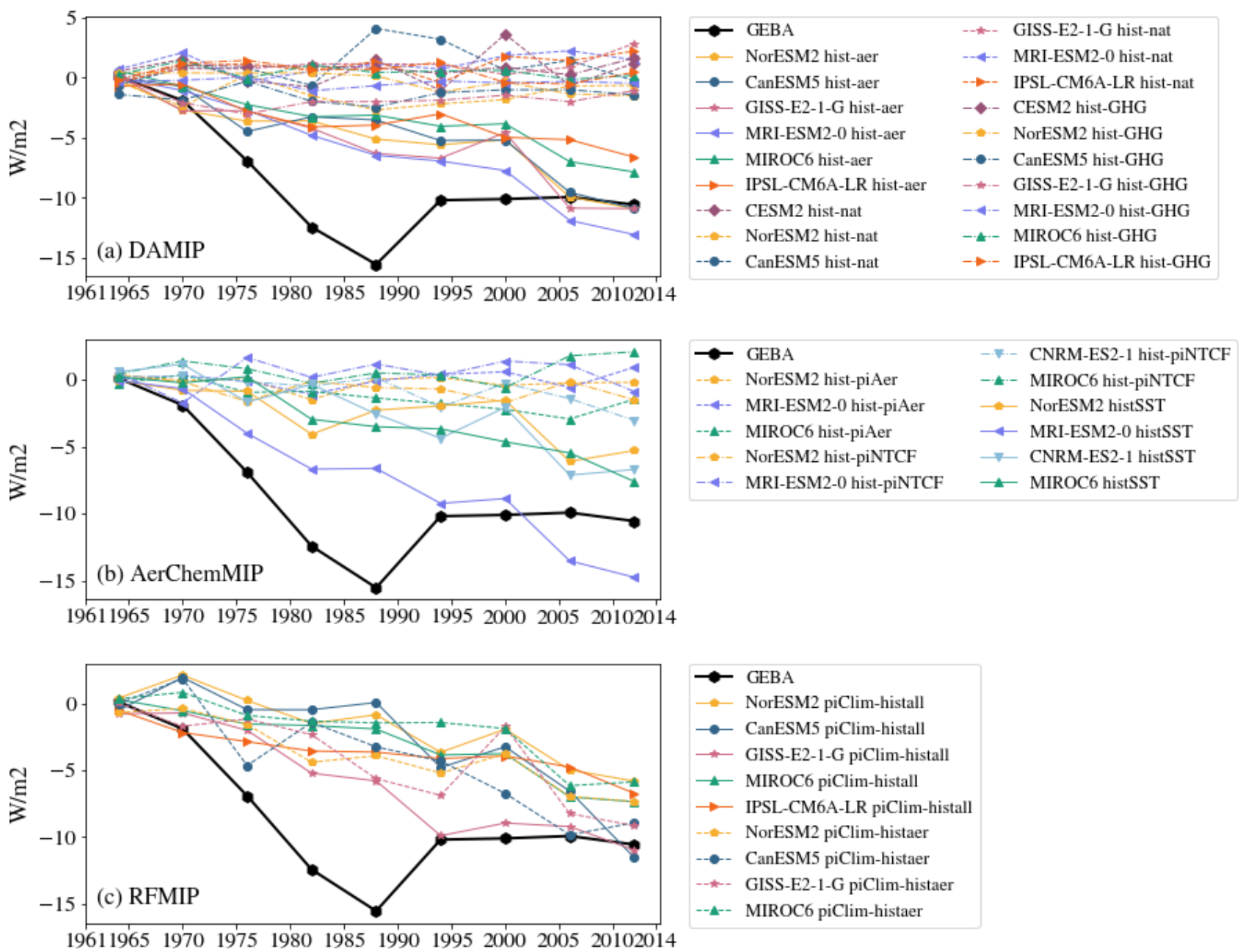

Figure 3. SDSR anomaly in China for all the CMIP6 simulations as listed in Table 1. All model results are co-located at GEBA station locations registered to China (119 stations). The entire 54-year period has been divided into intervals of 6 years and then averaged together to make nine data points as shown by the markers.

again supported by previous work mentioned in the introduction.

Overall there is a clear difference in SDSR between experiments that include anthropogenic aerosol emissions and experiments that do not. Dimming is apparent in every simulation containing anthropogenic aerosol emissions but absent in the simulations using aerosols maintained at constant preindustrial levels. This points to anthropogenic aerosol emissions playing a key role in dimming. Whether the sea surface temperature is pre-industrial, prescribed historical, or decided by a coupled ocean model seems to be unimportant for the SDSR temporal evolution in China in most models.

No distinct flattening or brightening is identified in any of the simulations in which dimming is identified, and therefore none of the model simulations shows a temporal evolution of SDSR close to the one seen in observations over China.

All-sky SDSR changes can be further decomposed by the models into a clear-sky contribution as well as a contribu- tion from changes in cloud cover or other cloud properties. In the next section we present the decomposed contributions to all-sky SDSR in China to further understand the discrepancy seen in Fig. 3.

\subsection{Clear-sky SDSR and cloud cover in China}

So far we have only evaluated all-sky SDSR, which is influenced by clouds and any aerosol radiative effects. Table 2 shows changes in cloud cover, all-sky SDSR, and clear-sky SDSR within three different time periods for the models and observational datasets of this study. Between the years 1961 and 1989 GEBA shows a strong negative change in all-sky SDSR in Fig. 2f. In Table 2 we thus show changes in this time period by making two 3-year means and subtracting them from one another. This is done to avoid extreme values as we are working with metrics exhibiting large year-to-year variations. This has been done for two additional time periods 
which have been chosen based on the temporal development in the all-sky SDSR as measured by GEBA in China (see Fig. 2f), summarized in the second lowest row in Table 2.

In the first time period the models do not agree on the sign of cloud cover change, and the simulated all-sky SDSR is weaker than the observed one, which was already established in the previous section. Clear-sky SDSR does not differ largely from all-sky SDSR within the models. For some models the negative change in clear-sky SDSR is stronger than in all-sky SDSR, meaning that the aerosol direct effect may contribute significantly to dimming for these models. The aerosol indirect effect changes the radiative properties of clouds in two ways: by making them appear brighter and by altering their lifetime (Boucher et al., 2013). Therefore, a weak change in cloud cover followed by a strong change in all-sky and clear-sky SDSR points to both the direct and brightening indirect aerosol effects being the primary cause of SDSR change, as an altered lifetime of clouds would imply cloud cover changes.

In the second time period GEBA shows a positive change (which will be further discussed in Sect. 4.1), and CRU shows a cloud cover change of $+3.0 \%$. Intuitively, an increase in cloud cover would not create a brightening at surface level. The observations are thus not consistent in this time period if only cloud cover effects were important. The models disagree in their sign of cloud cover changes and all-sky and clear-sky SDSR. In the final time period where GEBA shows a weak slightly positive change in all-sky SDSR, every model in this study shows a dimming. All models apart from MIROC6 show simulated clear-sky SDSR changes that are stronger than the changes found in all-sky SDSR. Together with the inconsistent simulated cloud cover and all-sky SDSR changes for this time period, we suggest that both direct and indirect aerosol effects are responsible for the changes in SDSR found in the model simulations.

All models show dimming in clear-sky and all-sky SDSR in the first and last time periods. Some models show a weak positive change in all-sky SDSR in the same period as GEBA presents a strong brightening. Both observed and simulated changes in cloud cover neither act as a brightening mask for clear-sky dimming nor are convincingly a cause of dimming/brightening in either observed or simulated allsky SDSR. A rough calculation of the effect of $1 \%$ cloud cover increase on SDSR in China is found in Sect. A3 in the Appendix, indicating that such an increase could result in a dimming of $1-3.5 \mathrm{~W} \mathrm{~m}^{-2}$. As such it shows that observed and modeled changes in cloud cover, as reported in Table 2, can lead to important contributions to the dimming and brightening signals in SDSR. However, this calculation is idealized, does not isolate the cloud cover change effect in the model results and does not explain the inconclusive data reported in Table 2. It is important to note that the robustness of observed cloud cover changes must be verified by satellite observations, which goes beyond the scope of this study.
In Sect. 3.3 we showed that dimming was only apparent in simulations that included anthropogenic aerosol emissions. In this section we found the clear-sky SDSR to be close in value to or even stronger than all-sky SDSR, indicating the simulated dimming is primarily caused by aerosol effects. Table 2 underlines previous findings: dimming in models is overall weaker than in observations. The next section will then show how the simulated aerosol burdens are connected to SDSR.

\subsection{Atmospheric burden of $\mathrm{SO}_{4}$}

In the atmosphere, the presence of a reflective aerosol is the cause of scattered shortwave radiation, and the emission of its precursor is only an indirect indicator of its presence. All CMIP6 simulations mentioned above have utilized the same anthropogenic sulfur dioxide gas emissions; however, the resultant dimming differed considerably. $\mathrm{SO}_{4}$ aerosol burdens should be more closely linked to the radiative effect. Therefore, we present here also the simulated anomalies in burden of $\mathrm{SO}_{4}$ in the various models over Europe, a location where dimming and brightening are fairly well represented in simulations, and over China, where dimming and brightening are poorly represented in simulations (Fig. $4 \mathrm{a}$ and b, respectively). The sulfate burdens are co-located to GEBA station locations in the respective regions. As expected, sulfate aerosols have an important role in European dimming and brightening, as the simulated burdens of $\mathrm{SO}_{4}$ show a strikingly similar pattern (but with opposite sign) to the observed SDSR over Europe for all the models. The maximum burdens are found in the early to mid 1980s depending on the model, and the minimum SDSR around the same time. The various models differ in the magnitude of change in $\mathrm{SO}_{4}$ burden over Europe, but all show similar tendencies. MRI-ESM20 is the model with the largest changes, and GISS-E2-1-G is the model with the smallest changes in $\mathrm{SO}_{4}$ burden. The same is observed over China, where MRI-ESM2-0 has an $\mathrm{SO}_{4}$ burden at the end of the time period which is more than double the burden of the other models (except NorESM2). In contrast to Europe, the observed SDSR evolution does not mirror well the simulated $\mathrm{SO}_{4}$ burden time series over the GEBA stations in China. In order for the $\mathrm{SO}_{4}$ burden to be the main cause of the observed changes in SDSR, the Asian $\mathrm{SO}_{4}$ burden would have to peak around the late 1980s, which is not seen in the models in Fig. 4b. All the simulated historical $\mathrm{SO}_{4}$ burdens increase until 2010, showing no signs of either a trend change or a flattening of aerosol-induced dimming. Assuming GEBA data provide a reasonable representation - within uncertainty bounds as discussed in Sect. 4.1 - of the historical development of SDSR and implicitly sulfur burdens in China, the problem in $\mathrm{SO}_{4}$ burden must come from either the emissions, aerosol formation, transport or the removal processes of $\mathrm{SO}_{4}$.

It appears, however, that the simulated burdens of $\mathrm{SO}_{4}$ co-located to GEBA stations in China follow quite closely 
Table 2. Changes in Chinese cloud cover (\%), all-sky SDSR AS ( $\mathrm{W} \mathrm{m}^{-2}$ ), and clear-sky SDSR CS (W m ${ }^{-2}$ ) between two 3-year means for three time periods. All model results are means made from three ensemble members of the historical simulation, co-located and extracted at Chinese GEBA station locations. Changes in cloud cover are from CRU gridded data and represent means co-located to Chinese GEBA stations.

\begin{tabular}{|c|c|c|c|c|c|c|c|c|c|}
\hline \multirow[b]{2}{*}{ Data } & \multicolumn{3}{|c|}{ [1961-1963]-[1987-1989] } & \multicolumn{3}{|c|}{ [1990-1992]-[1997-1999] } & \multicolumn{3}{|c|}{ [2000-2002]-[2012-2014] } \\
\hline & $(\%)$ & $\begin{array}{r}\mathrm{AS} \\
\left(\mathrm{W} \mathrm{m}^{-2}\right)\end{array}$ & $\begin{array}{r}\mathrm{CS} \\
\left(\mathrm{W} \mathrm{m}^{-2}\right)\end{array}$ & $(\%)$ & $\begin{array}{r}\mathrm{AS} \\
\left(\mathrm{W} \mathrm{m}^{-2}\right)\end{array}$ & $\begin{array}{r}\mathrm{CS} \\
\left(\mathrm{W} \mathrm{m}^{-2}\right)\end{array}$ & $(\%)$ & $\begin{array}{r}\mathrm{AS} \\
\left(\mathrm{W} \mathrm{m}^{-2}\right)\end{array}$ & $\begin{array}{r}\mathrm{CS} \\
\left(\mathrm{W} \mathrm{m}^{-2}\right)\end{array}$ \\
\hline NorESM2 & -1.0 & -4.6 & -4.0 & 0.6 & -1.0 & -0.4 & 0.3 & -3.9 & -5.0 \\
\hline CanESM5 & -0.4 & -3.5 & -4.6 & -0.1 & 0.8 & 0.6 & -1.7 & -2.4 & -5.7 \\
\hline MIROC6 & 0.4 & -4.4 & -3.6 & 1.2 & -1.3 & -0.4 & 0.5 & -5.5 & -5.3 \\
\hline CESM2 & -1.0 & -2.6 & -3.6 & -0.2 & 0.0 & -0.2 & 0.0 & -5.3 & -6.7 \\
\hline CNRM-ESM2-1 & -0.4 & -3.3 & -5.2 & -0.6 & 1.1 & -1.0 & -0.9 & -3.5 & -6.5 \\
\hline GISS-E2-1-G & 1.3 & -3.7 & -6.4 & -0.2 & -0.7 & -1.2 & 2.5 & -8.7 & -9.9 \\
\hline IPSL-CM6A-LR & -1.2 & -3.3 & -5.0 & 0.5 & -0.6 & -0.1 & -1.6 & -0.4 & -1.9 \\
\hline MRI-ESM2-0 & -0.1 & -7.1 & -6.9 & -0.3 & -0.8 & -0.9 & -1.1 & -4.9 & -8.8 \\
\hline MODELMEAN & -0.3 & -4.1 & -4.9 & 0.1 & -0.3 & -0.4 & -0.2 & -4.3 & -6.2 \\
\hline GEBA & & -15.4 & & & 6.6 & & & 0.9 & \\
\hline CRU & 0.1 & & & 3.0 & & & -1.0 & & \\
\hline
\end{tabular}
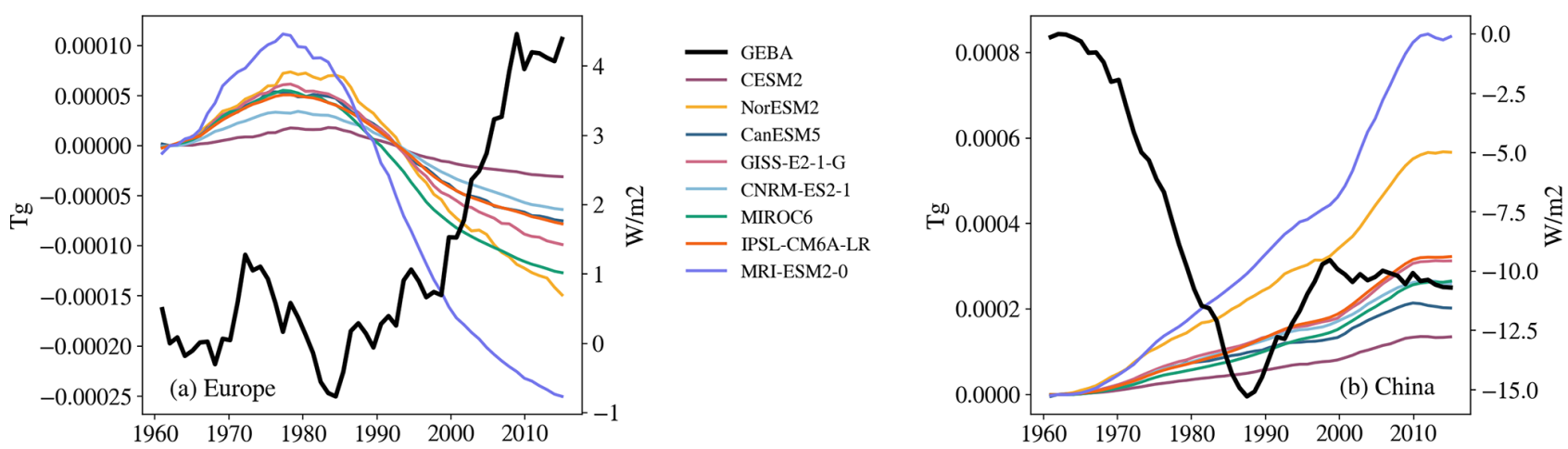

Figure 4. Anomaly of simulated atmospheric load of sulfate per model together with observed all-sky SDSR anomaly in (a) Europe and (b) China. The GEBA data are shown as yearly anomalies, while the atmospheric loads have been smoothed using a 10-year running mean technique as explained in Sect. 2.3.

the time series of emitted $\mathrm{SO}_{2}$ in the climate models over China (shown in Appendix Fig. A2), which indicates that $\mathrm{SO}_{4}$ formation and export of sulfur from the Chinese region remains rather similar in the period investigated. Following the logic that emission correlates with burden, which again anti-correlates with SDSR changes, the temporal development of SDSR seen in GEBA cannot be explained from the current emission inventories, given that sulfate aerosols play an important role in SDSR in China.

\section{Discussion}

The climate effect of aerosol emissions over the industrial era is poorly constrained, in part due to lack of observations and uncertainty in emissions. The uncertainty in past aerosol climate effects is an important reason for the large spread in climate projections for the future. Here, we investigate the effect of aerosols in GEBA which provides valuable observations of historical shortwave radiation at the surface.

We have shown that a subset of models participating in CMIP6 does not accurately represent the observed dimming and brightening trends globally and regionally in their historical simulation. This is comparable to that of Storelvmo et al. (2018) and Wild and Schmucki (2011), who showed that the CMIP5 and CMIP3 ensemble mean SDSR globally co-located to GEBA stations does not represent dimming or brightening. Our findings show that reproducibility of SDSR has not improved from CMIP5 to CMIP6. We find that most models show an underestimation of changes in SDSR compared to observations, and the development over time greatly differs between model and observations, especially in China. This is in agreement with Allen et al. (2013), who studied the CMIP5 ensemble mean and found a continuous dimming trend over China but with a severely underestimated magni- 
tude of modeled clear-sky SDSR during the dimming period compared to a clear-sky proxy based on GEBA data.

The simulated SDSR on decadal timescales over China does not differ significantly when comparing the RFMIP experiments (Fig. 3) to the historical experiment. RFMIP experiments have pre-industrial sea surface temperatures and thus do not include global-warming-induced cloud cover changes. When experiments with historical cloud cover changes show dimming in the same magnitude as experiments without historical cloud cover changes, the dimming can be assumed to be dominated by aerosol effects in China. This complements the findings by Folini and Wild (2015) where sea surface temperatures correlate with cloud cover, not aerosol effects. Table 2 showed inconclusive connections between modeled and observed cloud cover but clear connections between clear-sky SDSR and all-sky SDSR, again pointing to aerosol effects dominating SDSR time evolution in China.

The climate models strongly underestimate the dimming observed in China in addition to not representing the post1990 trend change. This trend change is the topic of discussion in the next section.

\subsection{The post-1990 trend change in China}

Several studies have tried to explain the trend change as presented here by GEBA in China in the transition from the 1980s to the 1990s. Streets et al. (2006) proposed a peak in combined emissions of $\mathrm{SO}_{2}$ and black carbon in 1988-1989 as a possible explanation. A later study questions the quality of the observational data showing the trend change (Tang et al., 2011), while recent studies propose the post-1990 initial, strong brightening is to a considerable extent an artifact of a nationwide change in SDSR measurements (Wang and Wild, 2016; Yang et al., 2018). The change in SDSR measurements includes a replacement of SDSR instrumentation, an increase in measurement frequency and in addition an update in the classification of SDSR stations, and Wang and Wild (2016) conclude that the upward trend ("jump" between 1990 and 1999) should be considerably weaker and that only $20 \%$ of the "jump" has actual physical causes. Yang et al. (2018) homogenized the data from Wang and Wild (2016) and Wang et al. (2012) and presented a new SDSR evolution (results can be seen in Yang et al., 2018, Fig. 10). The newly homogenized data exhibit a significant dimming trend $\left(-6.13 \pm 0.47 \mathrm{~W} \mathrm{~m}^{-2}\right.$ per decade) between 1958 and 1990, a flattening of the curve in 1991-2005, followed by a brightening trend $\left(6.13 \pm 1.77 \mathrm{~W} \mathrm{~m}^{-2}\right.$ per decade) between the years 2005 and 2016. We can use Fig. 2f to compare our model data to these homogenized data and see that even without a larger "jump" in the data around 1990 there are still large discrepancies between model and observation, both in the form and magnitude of the brightening period after 1990. All the models show dimming in the flattening period of the newly homogenized data. All the models apart from
CanESM5 show an averaged negative trend between the 6year means of 2003-2008 and 2009-2014, where the newly homogenized data show a brightening. A similar "jump" to the one seen in China can be identified slightly later in Japan (Fig. 2e). To our knowledge, we have no information on either a replacement of instruments or an update in the classification of SDSR stations in Japan. Norris and Wild (2009) investigated the role of clouds for historical SDSR observations in China and Japan and found the post-1990 brightening in Japan to be statistically significant, while the Chinese brightening was found to be insignificant. In this paper (published before Wang and Wild, 2016) half of the post-1990 brightening in China and one-third for Japan were attributed to a reduction in cloud cover. These results point to a need for more studies assessing and evaluating available observational SDSR data. However, models do not accurately represent the strength of dimming throughout the whole period or the change in trend after 1990 and thus the time evolution of SDSR observed in China, with or without the early 1990s "jump" in brightening.

\subsection{Aerosol effect on dimming}

Out of all the experiments presented in Table 1 and Fig. 3, only those containing anthropogenic aerosol emissions showed dimming. This is expected as aerosols have been presented as the main cause of reduction in SDSR in China by previous studies (Wild, 2009; Yunfeng et al., 2001; Kaiser and Qian, 2002).

Storelvmo et al. (2018) argue that the discrepancy seen between observed and modeled CMIP5 model mean global SDSR can be attributed to errors in the treatment of processes that translate aerosol emissions into clear-sky and allsky radiative forcings. Here, we can see an anti-correlation between simulated $\mathrm{SO}_{4}$ burdens from Fig. $4 \mathrm{a}$ and $\mathrm{b}$ and simulated SDSR from Fig. 2b and f, respectively. Therefore we suggest that the simulated SDSR is dominantly a result of simulated $\mathrm{SO}_{4}$ burdens. Simulated SDSR agrees relatively well with observed SDSR in Europe (Fig. 2b) along with simulated $\mathrm{SO}_{4}$ burden anti-correlating relatively well with observed SDSR in Europe (Fig. 4a). This means that the model code translating burdens into SDSR in Europe can simulate changes in SDSR as a consequence of changes in aerosol emissions. If models translate burden into SDSR correctly in Europe, this does not necessarily mean that they translate burden into SDSR correctly in other regions. However, we suggest that the code translating burdens into SDSR should also work correctly in China, since also in China we find that aerosols are the main cause of dimming, in agreement with Wild (2009), Yunfeng et al. (2001), and Kaiser and Qian (2002). Note also that we find no consistency between observed cloud cover changes, GEBA data and simulated cloud cover and SDSR anomalies in China (Table 2). By suggesting the translation process from burden to SDSR is behaving correctly in both regions, the potential source of 
error causing discrepancies between observed and simulated SDSR can be traced to the causes of the simulated atmospheric burdens in the first place.

The sulfur dioxide emission inventory used as input for historical model simulations in CMIP6 is shown in Hoesly et al. (2018) (Fig. 3), and the emissions as translated in four of the models of this study is shown in Fig. A2.

Hoesly et al. (2018) have pointed to the need for emission uncertainties, but this has not been done for these emissions. Aas et al. (2019) have studied global and regional trends in atmospheric sulfur and found that uncertainties in emissions were largest in Asia, even if their study only went back to 1990.

Previous studies estimating $\mathrm{SO}_{2}$ emissions include $\mathrm{Lu}$ et al. (2010), who found that sulfur dioxide emissions in China increased by 53\% between 2000 and 2006 using technology-based methodology and thereby found similar results to that of Hoesly et al. (2018). Lu et al. (2010) also compared AOD-derived SDSR to GEBA-based SDSR data as shown in Streets et al. (2006) and found the GEBA-based SDSR data to not accurately represent SDSR development in East Asia; this further underlines the need for more studies evaluating SDSR observations. Other studies such as Koukouli et al. (2018) have used satellite observations to estimate a new emission inventory for $\mathrm{SO}_{2}$ between 2005 and 2015 in China. We note that the year 2005 in Fig. A2 is directly after the sharp increase in $\mathrm{SO}_{2}$ emissions, and the biggest differences between the estimation made by Koukouli et al. (2018) and the $\mathrm{SO}_{2}$ emission inventories in CMIP6 are a decrease in emissions after the year of 2011. This decrease in $\mathrm{SO}_{2}$ emissions would intuitively result in a brightening, which is identified over the same time period in the homogenized data by Yang et al. (2018) (Fig. 10 therein).

The modeled emissions of $\mathrm{SO}_{2}$ as shown in Fig. A2 over China showed no trace of a significant change in trend after 1990 in our observed SDSR time series as discussed in the previous section. Assuming sulfate burden is responsible for the observed multiyear trends of SDSR, we argue that errors in emissions inventories in China could be part of the problem.

\section{Conclusions}

Earlier studies have shown that previous generations of Earth system models have not been able to reproduce the transient development of surface downwelling shortwave radiation (SDSR) in the last decades since 1960 when observations became available (Storelvmo et al., 2018; Allen et al., 2013). This discrepancy is hypothesized to be related to increasing and then partially decreasing trends in global aerosol emissions and subsequent aerosol radiative effects, but the exact cause is unknown.
In this paper, we compared observations to modelsimulated surface downwelling shortwave radiation and cloud cover in specific regions for the time period 1961 to 2014. We found that in the historical experiments, CMIP6 models reproduce the transient development of SDSR well in Europe but poorly in Asia. The multiple historical and associated perturbation experiments performed under CMIP6 reveal that only those simulations containing anthropogenic aerosol emissions show dimming, and the dimming is underestimated by most models. China exhibits a sharp positive trend in observed SDSR in the 1990s that is not found in historical model simulations. This "jump" has been suggested to be an artifact, but historical simulations also do not accurately represent the homogenized observed SDSR as proposed by Yang et al. (2018). We suggest that the continuous decrease in simulated SDSR is related to the continuous increase in atmospheric sulfate burden in the historical simulations over China. Following this logic, the observed transient development of SDSR points to the evolution of the sulfate burden in the models being wrong in this region. The sulfate burden is a result of sulfur dioxide emissions, gas-to-particle conversion and wet deposition. Sulfur dioxide emissions over China show neither sign of the observed trend change from gap-filled GEBA data nor of the brightening-followed flattening from the homogenized data as proposed by Yang et al. (2018). Sulfur dioxide emissions used in the models over China have a strong increase in the early 2000s, which can be observed as a sharp dimming at the same time in Fig. $2 \mathrm{f}$. We suggest that the cause of the discrepancy between model and observations in transient SDSR in China is partly in erroneous emission inventories.

As the observed climate change is the result of warming from greenhouse gases and simultaneous cooling from aerosol radiative effects, getting aerosol emissions correct is important in Earth system models.

Since the SDSR measurements are not only sensitive to aerosol effects, they might not be the most accurate way to infer historic aerosol loads and forcing. Further studies could include other observations and proxies for aerosol effects in the historical era, such as long-term satellite-retrieved aerosol optical depth, deposition of anthropogenic sulfur, organic carbon and nitrate in ice cores, as well as daily temperature range records. 


\section{Appendix A: Additional information}

\section{A1 The European SDSR evolution}

Figure A1 suggests cloud cover variation as a possible explanation of the local maximum in observed European SDSR during the period 1967-1978. Cloud cover exhibited a substantial minimum simultaneous with the maximum in SDSR. The peak is not reproduced in the historical runs of Earth system models studied herein (see Fig. 2b). Cloud cover variations that are not externally forced but are rather a result of internal variability cannot be expected to be reproduced in fully coupled Earth system models. This might serve as an explanation why the substantial peak in SDSR between 1967 and 1978 is not reproduced in the Earth system models.

\section{A2 The data downloaded from ESGF}

Table A2 shows an overview of the eight models used in this study. For the historical simulations three ensemble members per model were downloaded, with the variant labels $\mathrm{r}[1,2,3] \mathrm{i} 1 \mathrm{p} 1 \mathrm{f}[1,2]$ for the variables rsds, rsdscs and clt. In addition, the variables loadso 4 and areacella were downloaded for one ensemble member per model in the historical simulation per model. In the remaining experiments listed in Table 1 only one ensemble member per model was downloaded for the variable rsds; this was done as not every model provides more than one simulation per experiment.

\section{A3 Effects of cloud cover change on all-sky SDSR}

If we assume that $E_{\text {clear sky }}$ is the diurnal average clear-sky SDSR in a region and that $\tau_{\text {cloud }}$ is the average cloud optical depth, we can compute idealized effects of cloud changes on SDSR using the Beer-Lambert law:

$E_{\text {surf }}=E_{\text {toa }} \exp (-\tau / \cos \phi)$,

where $\tau$ and $\phi$ denote optical depth and solar zenith angle, respectively. The change in SSR per $1 \%$ change in cloud cover can then be computed:

$$
\begin{aligned}
\Delta E_{\text {surf per } 1 \%} & =0.01 \times E_{\text {cloudy }}-E_{\text {clear sky }}=0.01 \\
& \times E_{\text {toa }} \exp \left(-\tau_{\text {cloud }} / \cos \phi\right. \\
& \left.+\ln \left(E_{\text {clear sky }} / E_{\text {toa }}\right)\right)+0.99 \times E_{\text {clear sky }} \\
& -E_{\text {clear sky }} .
\end{aligned}
$$

Idealized computation for China. Assuming that $\phi$ is between 30 and $70^{\circ}$, that $E_{\text {clear sky }}$ is between 100 and $350 \mathrm{~W} \mathrm{~m}^{-2}$ and that $E_{\mathrm{toa}}=1362 \mathrm{~W} \mathrm{~m}^{-2}$ in China, the theoretical effect of $1 \%$ increase in cloud cover on all-sky SDSR is between -1 and $-3.5 \mathrm{~W} \mathrm{~m}^{-2}$, using the idealized computation described above.

Table A1. Global all-sky SDSR and cloud cover averaged over the years 1961-1966 (baseline values) as observed (GEBA for radiation, CRU for cloud cover) and as simulated in the ensemble mean of three ensemble members in the historical experiment by each of the models of this study. Data from both CRU and models are retrieved after co-location to all GEBA sites.

\begin{tabular}{lrr}
\hline Model & SDSR $\left(\mathrm{W} \mathrm{m}^{-2}\right)$ & Cloud cover $(\%)$ \\
\hline CESM2 & 186.3 & 63.9 \\
NorESM2 & 186.8 & 55.6 \\
CanESM5 & 189.5 & 56.2 \\
GISS-E2-1-G & 176.6 & 58.6 \\
MRI-ESM2-0 & 193.8 & 56.2 \\
CNRM-ES2-1 & 192.3 & 57.2 \\
MIROC6 & 184.3 & 50.4 \\
IPSL-CM6A-LR & 185.7 & 54.5 \\
CRU & & $\mathbf{5 7 . 4}$ \\
GEBA & $\mathbf{1 7 1 . 6}$ & \\
\hline
\end{tabular}


Table A2. Details on the models used. IA: interactive aerosols. NIA: non-interactive aerosols.

\begin{tabular}{llllll}
\hline Institution & Model & Resolution & Aerosol module & Complexity & Reference \\
\hline NCAR & CESM2 & $1.25 \times 0.9$ & MAM4 & IA & Danabasoglu et al. (2020) \\
CCCma & CanESM5 & $2.81 \times 2.81$ & CanAM4 & IA & Swart et al. (2019) \\
CNRM-CERFACS & CNRM-ESM2-1 & $1.4 \times 1.4$ & TACTIC_v2 & IA & Séférian et al. (2019) \\
IPSL & IPSL-CM6A-LR & $2.5 \times 1.27$ & INCA fields & NIA & Boucher et al. (2020) \\
NCC & NorESM2-LM & $2.5 \times 1.875$ & OsloAero6 & IA & Seland et al. (2020) \\
MRI & MRI-ESM2-0 & $1.125 \times 1.125$ & MASINGAR mk-2r4c & IA & Yukimoto et al. (2019) \\
MIROC & MIROC6 & $1.4 \times 1.4$ & SPRINTARS & IA & Tatebe et al. (2019) \\
NASA-GISS & GISS-E2-1-G & $2.5 \times 2.0$ & OMA fields & NIA & Kelley et al. (2020) \\
\hline
\end{tabular}

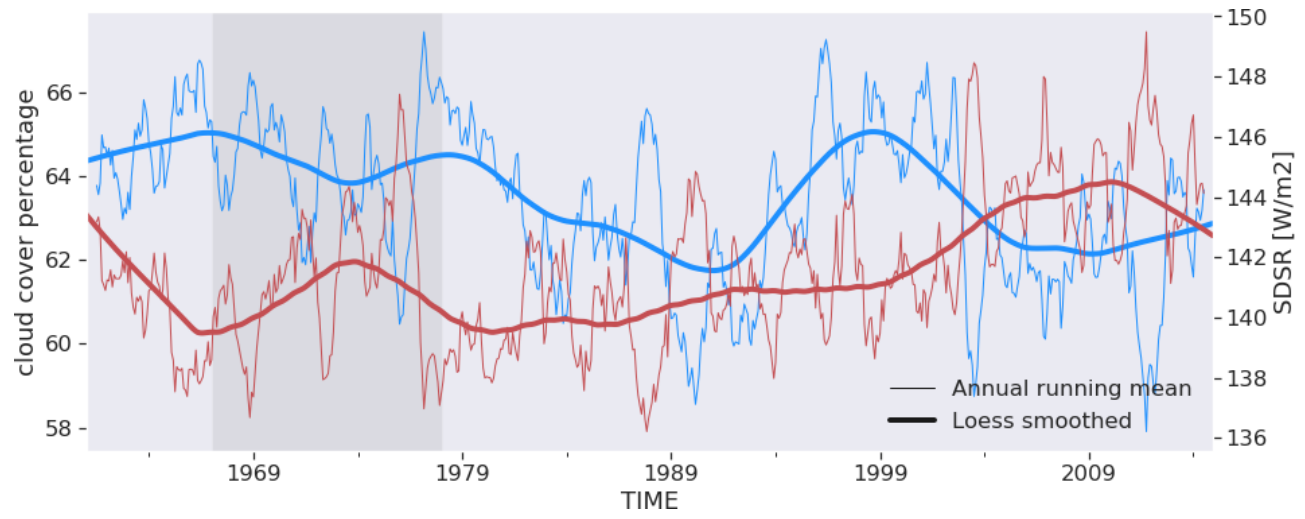

Figure A1. Time series of cloud cover (blue) and SDSR (red) between 1961 and 2014, co-located at GEBA sites in Europe. Thin lines show annual running means; bold lines show LOESS-smoothed variants. The shaded area delineates a period of interrupted dimming in Europe, between 1967 and 1978, which occurred simultaneously with a local minimum in the cloud cover trend.

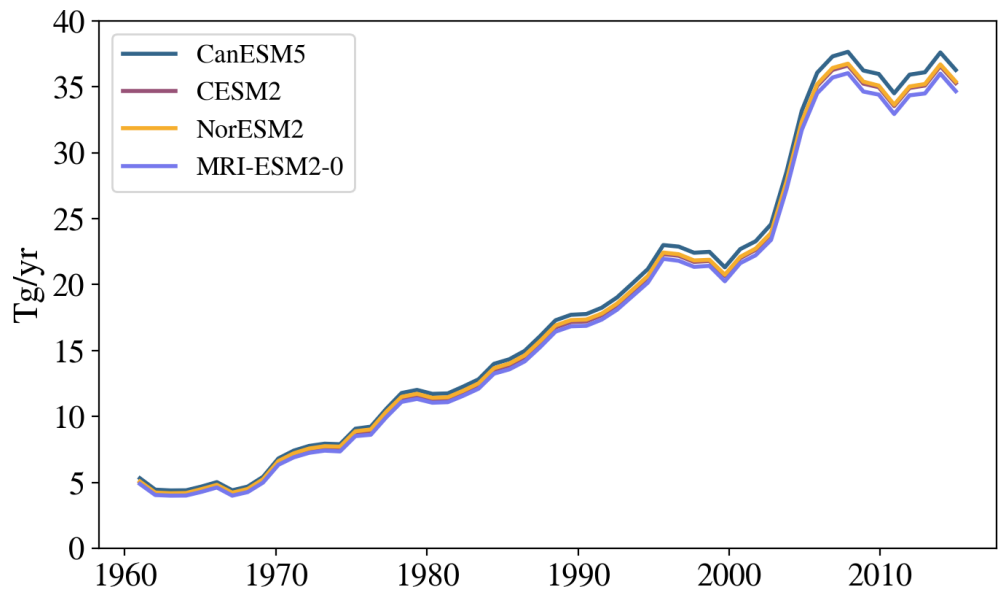

Figure A2. Emission of $\mathrm{SO}_{2}$ in China, diagnosed by four of the models in this study. China is defined here as the area within latitudes $\left[20-45^{\circ} \mathrm{N}\right]$ and longitudes $\left[95-125^{\circ} \mathrm{E}\right]$. 
Code and data availability. CMIP6 model outputs are freely available from the World Climate Research Programme (WCRP), 2011; https://esgf-node.llnl.gov/search/cmip6/ (WCRP, 2020). CRU TS v4.02 used for the cloud cover analysis is available from the University of East Anglia's website: https://crudata.uea.ac.uk/cru/data/ hrg/ (University og East Anglia, 2020). The gap-filled GEBA data is available https://doi.org/10.5281/zenodo.4382033 (Storelvmo, 2020).

Author contributions. KOM wrote most of the article and did all analysis of CMIP6 data. MS and TS contributed to the design of the study and helped edit the text. DO, PN, JNSC, TT, NO, SEB, and GG contributed model data via the ESGF CMIP6 archive. IRJ and MW contributed with observational data, and IRJ wrote part of the Appendix. All the co-authors contributed to the analysis and gave feedback on the manuscript.

Competing interests. The authors declare that they have no conflict of interest.

Acknowledgements. This study benefited greatly from the CMIP6 data infrastructure for handling and providing model data for analysis. Jan Griesfeller is thanked for data organization. Highperformance computing and storage resources were provided by the Norwegian infrastructure for computational science (through projects NS2345K, NS9560K and NS9252K) and the Norwegian Meteorological Institute. Toshihiko Takemura was supported by the supercomputer system of the National Institute for Environmental Studies, Japan, and JSPS KAKENHI grant no. JP19H05669. Naga Oshima was supported by the Japan Society for the Promotion of Science (grant nos. JP18H03363, JP18H05292 and JP20K04070), the Environment Research and Technology Development Fund (JPMEERF20172003, JPMEERF20202003 and JPMEERF20205001) of the Environmental Restoration and Conservation Agency of Japan, the Arctic Challenge for Sustainability II (ArCS II), programme grant no. JPMXD1420318865, and a grant for the Global Environmental Research Coordination System from the Ministry of the Environment, Japan. GEBA is supported by the Federal Office of Meteorology and Climatology, MeteoSwiss, in the framework of GCOS Switzerland. Martin Wild is grateful for funding obtained from the Swiss National Science Foundation, grant no. 200020_188601.

Financial support. This research has been supported by the European Union's Horizon 2020 (FORCeS) (grant no. 821205) and the Research Council of Norway (KeyClim) (grant no. 295046).

Review statement. This paper was edited by Jui-Yuan Christine Chiu and reviewed by two anonymous referees.

\section{References}

Aas, W., Mortier, A., Bowersox, V., Cherian, R., Faluvegi, G., Fagerli, H., Hand, J., Klimont, Z., Galy-Lacaux, C., Lehmann, C. M. B., Myhre, C. L., Myhre, G., Olivié, D., Sato, K., Quaas, J., Rao, P. S. P., Schulz, M., Shindell, D., Skeie, R. B., Stein, A., Takemura, T., Tsyro, S., Vet, R., and Xu, X.: Global and regional trends of atmospheric sulfur, Sci. Rep.-UK, 9, 953, https://doi.org/10.1038/s41598-018-37304-0, 2019.

Allen, R. J., Norris, J. R., and Wild, M.: Evaluation of multidecadal variability in CMIP5 surface solar radiation and inferred underestimation of aerosol direct effects over Europe, China, Japan, and India, J. Geophys. Res.-Atmos., 118, 6311-6336, https://doi.org/10.1002/jgrd.50426, 2013.

Boucher, O., Randall, D., Artaxo, P., Bretherton, C., Feingold, G., Forster, P., Kerminen, V.-M., Kondo, Y., Liao, H., Lohmann, U., Rasch, P., Satheesh, S., Sherwood, S., Stevens, B., and Zhang, X.: Clouds and Aerosols, Cambridge University Press, Cambridge, UK and New York, NY, USA, https://doi.org/10.1017/CBO9781107415324.016, 2013.

Boucher, O., Servonnat, J., Albright, A. L., Aumont, O., Balkanski, Y., Bastrikov, V., Bekki, S., Bonnet, R., Bony, S., Bopp, L., Braconnot, P., Brockmann, P., Cadule, P., Caubel, A., Cheruy, F., Codron, F., Cozic, A., Cugnet, D., D’Andrea, F., Davini, P., Lavergne, C. D., Denvil, S., Deshayes, J., Devilliers, M., Ducharne, A., Dufresne, J.-L., Dupont, E., Ãtha, C., Fairhead, L., Falletti, L., Flavoni, S., Foujols, M.-A., Gardoll, S., Gastineau, G., Ghattas, J., Grandpeix, J.-Y., Guenet, B., Guez, E., L., Guilyardi, E., Guimberteau, M., Hauglustaine, D., Hourdin, F., Idelkadi, A., Joussaume, S., Kageyama, M., Khodri, M., Krinner, G., Lebas, N., Levavasseur, G., Lavy, C., Li, L., Lott, F., Lurton, T., Luyssaert, S., Madec, G., Madeleine, J.B., Maignan, F., Marchand, M., Marti, O., Mellul, L., Meurdesoif, Y., Mignot, J., Musat, I., Ottla, C., Peylin, P., Planton, Y., Polcher, J., Rio, C., Rochetin, N., Rousset, C., Sepulchre, P., Sima, A., Swingedouw, D., Thiablemont, R., Traore, A. K., Vancoppenolle, M., Vial, J., Vialard, J., Viovy, N., and Vuichard, N.: Presentation and Evaluation of the IPSL-CM6A-LR Climate Model, J. Adv. Model. Earth Sy., 12, e2019MS002010, https://doi.org/10.1029/2019MS002010, 2020.

Breiman, L.: Random Forests, Machine Learning, 45, 5-32, https://doi.org/10.1023/A:1010933404324, 2001.

Cinquini, L., Crichton, D., Mattmann, C., Harney, J., Shipman, G., Wang, F., Ananthakrishnan, R., Miller, N., Denvil, S., Morgan, M., Pobre, Z., Bell, G. M., Doutriaux, C., Drach, R., Williams, D., Kershaw, P., Pascoe, S., Gonzalez, E., Fiore, S., and Schweitzer, R.: The Earth System Grid Federation: An open infrastructure for access to distributed geospatial data, Future Gener. Comp. Sy., 36, 400-417, https://doi.org/10.1016/j.future.2013.07.002, 2014.

Collins, W. J., Lamarque, J.-F., Schulz, M., Boucher, O., Eyring, V., Hegglin, M. I., Maycock, A., Myhre, G., Prather, M., Shindell, D., and Smith, S. J.: AerChemMIP: quantifying the effects of chemistry and aerosols in CMIP6, Geosci. Model Dev., 10, 585607, https://doi.org/10.5194/gmd-10-585-2017, 2017.

Danabasoglu, G., Lamarque, J.-F., Bacmeister, J., Bailey, D. A., DuVivier, A. K., Edwards, J., Emmons, L. K., Fasullo, J., Garcia, R., Gettelman, A., Hannay, C., Holland, M. M., Large, W. G., Lauritzen, P. H., Lawrence, D. M., Lenaerts, J. T. M., Lindsay, K., Lipscomb, W. H., Mills, M. J., Neale, R., Ole- 
son, K. W., Otto-Bliesner, B., Phillips, A. S., Sacks, W., Tilmes, S., Kampenhout, L. v., Vertenstein, M., Bertini, A., Dennis, J., Deser, C., Fischer, C., Fox-Kemper, B., Kay, J. E., Kinnison, D., Kushner, P. J., Larson, V. E., Long, M. C., Mickelson, S., Moore, J. K., Nienhouse, E., Polvani, L., Rasch, P. J., and Strand, W. G.: The Community Earth System Model Version 2 (CESM2), J. Adv. Model. Earth Sy., 12, e2019MS001916, https://doi.org/10.1029/2019MS001916, 2020.

Eddy, J. A., Gilliland, R. L., and Hoyt, D. V.: Changes in the solar constant and climatic effects, Nature, 300, 689-693, https://doi.org/10.1038/300689a0, 1982.

Eyring, V., Bony, S., Meehl, G. A., Senior, C. A., Stevens, B., Stouffer, R. J., and Taylor, K. E.: Overview of the Coupled Model Intercomparison Project Phase 6 (CMIP6) experimental design and organization, Geosci. Model Dev., 9, 1937-1958, https://doi.org/10.5194/gmd-9-1937-2016, 2016.

Fan, C., Shannigrahi, S., DiBenedetto, S., Olschanowsky, C., Papadopoulos, C., and Newman, H.: Managing Scientific Data with Named Data Networking, in: Proceedings of the Fifth International Workshop on Network-Aware Data Management, Austin, TX, USA, 15-20 November 2015, 1-7, 2015.

Folini, D. and Wild, M.: The effect of aerosols and sea surface temperature on China's climate in the late twentieth century from ensembles of global climate simulations, J. Geophys. Res.-Atmos., 120, 2261-2279, https://doi.org/10.1002/2014JD022851, 2015.

Gillett, N. P., Shiogama, H., Funke, B., Hegerl, G., Knutti, R., Matthes, K., Santer, B. D., Stone, D., and Tebaldi, C.: The Detection and Attribution Model Intercomparison Project (DAMIP v1.0) contribution to CMIP6, Geosci. Model Dev., 9, 3685-3697, https://doi.org/10.5194/gmd-9-3685-2016, 2016.

Harris, I., Osborn, T. J., Jones, P., and Lister, D.: Version 4 of the CRU TS monthly high-resolution gridded multivariate climate dataset, Scientific Data, 7, 109, https://doi.org/10.1038/s41597020-0453-3, 2020.

Hoesly, R. M., Smith, S. J., Feng, L., Klimont, Z., JanssensMaenhout, G., Pitkanen, T., Seibert, J. J., Vu, L., Andres, R. J., Bolt, R. M., Bond, T. C., Dawidowski, L., Kholod, N., Kurokawa, J.-I., Li, M., Liu, L., Lu, Z., Moura, M. C. P., O'Rourke, P. R., and Zhang, Q.: Historical (1750-2014) anthropogenic emissions of reactive gases and aerosols from the Community Emissions Data System (CEDS), Geosci. Model Dev., 11, 369-408, https://doi.org/10.5194/gmd-11-369-2018, 2018.

Hoyt, D. V. and Schatten, K. H.: A discussion of plausible solar irradiance variations, 1700-1992, J. Geophys. Res.-Space, 98, 18895-18906, https://doi.org/10.1029/93JA01944, 1993.

Kaiser, D. P. and Qian, Y.: Decreasing trends in sunshine duration over China for 1954-1998: Indication of increased haze pollution?, Geophys. Res. Lett., 29, 1-4, https://doi.org/10.1029/2002GL016057, 2002.

Kelley, M., Schmidt, G. A., Nazarenko, L. S., Bauer, S. E., Ruedy, R., Russell, G. L., Ackerman, A. S., Aleinov, I., Bauer, M., Bleck, R., Canuto, V., Cesana, G., Cheng, Y., Clune, T. L., Cook, B. I., Cruz, C. A., Genio, A. D. D., Elsaesser, G. S., Faluvegi, G., Kiang, N. Y., Kim, D., Lacis, A. A., Leboissetier, A., LeGrande, A. N., Lo, K. K., Marshall, J., Matthews, E. E., McDermid, S., Mezuman, K., Miller, R. L., Murray, L. T., Oinas, V., Orbe, C., GarcíaPando, C. P., Perlwitz, J. P., Puma, M. J., Rind, D., Romanou, A., Shindell, D. T., Sun, S., Tausnev, N., Tsigaridis, K., Tselioudis, G., Weng, E., Wu, J., and Yao, M.-S.: GISS-
E2.1: Configurations and Climatology, J. Adv. Model. Earth Sy., 12, e2019MS002025, https://doi.org/10.1029/2019MS002025, 2020.

Koukouli, M. E., Theys, N., Ding, J., Zyrichidou, I., Mijling, B., Balis, D., and van der A, R. J.: Updated $\mathrm{SO}_{2}$ emission estimates over China using OMI/Aura observations, Atmos. Meas. Tech., 11, 1817-1832, https://doi.org/10.5194/amt-111817-2018, 2018.

Liepert, B. G.: Observed reductions of surface solar radiation at sites in the United States and worldwide from 1961 to 1990, Geophys. Res. Lett., 29, 1-4, https://doi.org/10.1029/2002GL014910, 2002.

Lu, Z., Streets, D. G., Zhang, Q., Wang, S., Carmichael, G. R., Cheng, Y. F., Wei, C., Chin, M., Diehl, T., and Tan, Q.: Sulfur dioxide emissions in China and sulfur trends in East Asia since 2000, Atmos. Chem. Phys., 10, 6311-6331, https://doi.org/10.5194/acp-10-6311-2010, 2010.

Michalsky, J., Dutton, E., Rubes, M., Nelson, D., Stoffel, T., Wesley, M., Splitt, M., and DeLuisi, J.: Optimal Measurement of Surface Shortwave Irradiance Using Current Instrumentation, J. Atmos. Oceanic Technol., 16, 55-69, https://doi.org/10.1175/15200426(1999)016<0055:OMOSSI>2.0.CO;2, 1999.

Nabat, P., Somot, S., Mallet, M., Sanchez-Lorenzo, A., and Wild, M.: Contribution of anthropogenic sulfate aerosols to the changing Euro-Mediterranean climate since 1980, Geophys. Res. Lett., 41, 5605-5611, https://doi.org/10.1002/2014GL060798, 2014.

Norris, J. R. and Wild, M.: Trends in aerosol radiative effects over China and Japan inferred from observed cloud cover, solar "dimming" and solar "brightening", J. Geophys. Res.-Atmos., 114, D00D15, https://doi.org/10.1029/2008JD011378, 2009.

Pincus, R., Forster, P. M., and Stevens, B.: The Radiative Forcing Model Intercomparison Project (RFMIP): experimental protocol for CMIP6, Geosci. Model Dev., 9, 3447-3460, https://doi.org/10.5194/gmd-9-3447-2016, 2016.

Ramanathan, V. and Vogelmann, A. M.: Greenhouse Effect, Atmospheric Solar Absorption and the Earth's Radiation Budget: From the Arrhenius-Langley Era to the 1990s, Ambio, 26, 38 46, 1997.

Ramanathan, V., Cess, R. D., Harrison, E. F., Minnis, P., Barkstrom, B. R., Ahmad, E., and Hartmann, D.: Cloud-radiative forcing and climate: results from the Earth radiation budget experiment, Science, 243, 57-63, https://doi.org/10.1126/science.243.4887.57, 1989.

Romanou, A., Liepert, B., Schmidt, G. A., Rossow, W. B., Ruedy, R. A., and Zhang, Y.: 20th century changes in surface solar irradiance in simulations and observations, Geophys. Res. Lett., 34, L05713, https://doi.org/10.1029/2006GL028356, 2007.

Sanchez-Romero, A., Sanchez-Lorenzo, A., Calbó, J., González, J. A., and Azorin-Molina, C.: The signal of aerosolinduced changes in sunshine duration records: A review of the evidence, J. Geophys. Res.-Atmos., 119, 4657-4673, https://doi.org/10.1002/2013JD021393, 2014.

Séférian, R., Nabat, P., Michou, M., Saint-Martin, D., Voldoire, A., Colin, J., Decharme, B., Delire, C., Berthet, S., Chevallier, M., Sénési, S., Franchisteguy, L., Vial, J., Mallet, M., Joetzjer, E., Geoffroy, O., Guérémy, J.-F., Moine, M.-P., Msadek, R., Ribes, A., Rocher, M., Roehrig, R., Salas-y-Mélia, D., Sanchez, E., Terray, L., Valcke, S., Waldman, R., Aumont, O., Bopp, L., Deshayes, J., Éthé, C., and Madec, G.: Evaluation of CNRM Earth Sys- 
tem Model, CNRM-ESM2-1: Role of Earth System Processes in Present-Day and Future Climate, J. Adv. Model. Earth Sy., 11, 4182-4227, https://doi.org/10.1029/2019MS001791, 2019.

Seland, Ø., Bentsen, M., Seland Graff, L., Olivié, D., Toniazzo, T., Gjermundsen, A., Debernard, J. B., Gupta, A. K., He, Y., Kirkevåg, A., Schwinger, J., Tjiputra, J., Schancke Aas, K., Bethke, I., Fan, Y., Griesfeller, J., Grini, A., Guo, C., Ilicak, M., Hafsahl Karset, I. H., Landgren, O., Liakka, J., Onsum Moseid, K., Nummelin, A., Spensberger, C., Tang, H., Zhang, Z., Heinze, C., Iverson, T., and Schulz, M.: The Norwegian Earth System Model, NorESM2 - Evaluation of theCMIP6 DECK and historical simulations, Geosci. Model Dev. Discuss., https://doi.org/10.5194/gmd-2019-378, in review, 2020.

Smith, C. J., Kramer, R. J., Myhre, G., Alterskjær, K., Collins, W., Sima, A., Boucher, O., Dufresne, J.-L., Nabat, P., Michou, M., Yukimoto, S., Cole, J., Paynter, D., Shiogama, H., O'Connor, F. M., Robertson, E., Wiltshire, A., Andrews, T., Hannay, C., Miller, R., Nazarenko, L., Kirkevåg, A., Olivié, D., Fiedler, S., Lewinschal, A., Mackallah, C., Dix, M., Pincus, R., and Forster, P. M.: Effective radiative forcing and adjustments in CMIP6 models, Atmos. Chem. Phys., 20, 9591-9618, https://doi.org/10.5194/acp-20-9591-2020, 2020.

Solomon, S., Rosenlof, K. H., Portmann, R. W., Daniel, J. S., Davis, S. M., Sanford, T. J., and Plattner, G.-K.: Contributions of Stratospheric Water Vapor to Decadal Changes in the Rate of Global Warming, Science, 327, 1219-1223, https://doi.org/10.1126/science.1182488, 2010.

Storelvmo, T.: Gap filled GEBA data [Data set], Zenodo, https://doi.org/10.5281/zenodo.4382033, 2020.

Storelvmo, T., Heede, U. K., Leirvik, T., Phillips, P. C. B., Arndt, P., and Wild, M.: Lethargic Response to Aerosol Emissions in Current Climate Models, Geophys. Res. Lett., 45, 9814-9823, https://doi.org/10.1029/2018GL078298, 2018.

Streets, D. G., Wu, Y., and Chin, M.: Two-decadal aerosol trends as a likely explanation of the global dimming/brightening transition, Geophys. Res. Lett., 33, L15806, https://doi.org/10.1029/2006GL026471, 2006.

Swart, N. C., Cole, J. N. S., Kharin, V. V., Lazare, M., Scinocca, J. F., Gillett, N. P., Anstey, J., Arora, V., Christian, J. R., Hanna, S., Jiao, Y., Lee, W. G., Majaess, F., Saenko, O. A., Seiler, C., Seinen, C., Shao, A., Sigmond, M., Solheim, L., von Salzen, K., Yang, D., and Winter, B.: The Canadian Earth System Model version 5 (CanESM5.0.3), Geosci. Model Dev., 12, 4823-4873, https://doi.org/10.5194/gmd-12-4823-2019, 2019.

Tang, W.-J., Yang, K., Qin, J., Cheng, C. C. K., and He, J.: Solar radiation trend across China in recent decades: a revisit with quality-controlled data, Atmos. Chem. Phys., 11, 393-406, https://doi.org/10.5194/acp-11-393-2011, 2011.

Tatebe, H., Ogura, T., Nitta, T., Komuro, Y., Ogochi, K., Takemura, T., Sudo, K., Sekiguchi, M., Abe, M., Saito, F., Chikira, M., Watanabe, S., Mori, M., Hirota, N., Kawatani, Y., Mochizuki, T., Yoshimura, K., Takata, K., O’ishi, R., Yamazaki, D., Suzuki, T., Kurogi, M., Kataoka, T., Watanabe, M., and Kimoto, M.: Description and basic evaluation of simulated mean state, internal variability, and climate sensitivity in MIROC6, Geosci. Model Dev., 12, 2727-2765, https://doi.org/10.5194/gmd-122727-2019, 2019.
University og East Anglia: CRU TS v4.02 cloud cover data, available at: https://crudata.uea.ac.uk/cru/data/hrg/, last access: September 2020.

Wang, K. C., Dickinson, R. E., Wild, M., and Liang, S.: Atmospheric impacts on climatic variability of surface incident solar radiation, Atmos. Chem. Phys., 12, 9581-9592, https://doi.org/10.5194/acp-12-9581-2012, 2012.

Wang, Y. and Wild, M.: A new look at solar dimming and brightening in China: CHINA DIMMING AND BRIGHTENING REVISITED, Geophys. Res. Lett., 43, 11777-11785, https://doi.org/10.1002/2016GL071009, 2016.

Wang, Y. W. and Yang, Y. H.: China's dimming and brightening: evidence, causes and hydrological implications, Ann. Geophys., 32, 41-55, https://doi.org/10.5194/angeo-32-41-2014, 2014.

WCRP: CMIP6 project data, available at: https://esgf-node.llnl.gov/ search/cmip6/, last access: December 2020.

Wild, M.: Global dimming and brightening: A review, J. Geophys. Res., 114, D00D16, https://doi.org/10.1029/2008JD011470, 2009 .

Wild, M.: Decadal changes in radiative fluxes at land and ocean surfaces and their relevance for global warming, Wires Climate Change, 7, 91-107, https://doi.org/10.1002/wcc.372, 2016.

Wild, M. and Schmucki, E.: Assessment of global dimming and brightening in IPCC-AR4/CMIP3 models and ERA40, Clim Dynam, 37, 1671-1688, https://doi.org/10.1007/s00382-010-09393, 2011 .

Wild, M., Gilgen, H., Roesch, A., Ohmura, A., Long, C. N., Dutton, E. G., Forgan, B., Kallis, A., Russak, V., and Tsvetkov, A.: From Dimming to Brightening: Decadal Changes in Solar Radiation at Earth's Surface, Science, 308, 847-850, https://doi.org/10.1126/science.1103215, 2005.

Wild, M., Ohmura, A., and Makowski, K.: Impact of global dimming and brightening on global warming, Geophys. Res. Lett., 34, L04702, https://doi.org/10.1029/2006GL028031, 2007.

Wild, M., Folini, D., Schär, C., Loeb, N., Dutton, E. G., and König-Langlo, G.: The global energy balance from a surface perspective, Clim. Dynam., 40, 3107-3134, https://doi.org/10.1007/s00382-012-1569-8, 2013.

Wild, M., Ohmura, A., Schär, C., Müller, G., Folini, D., Schwarz, M., Hakuba, M. Z., and Sanchez-Lorenzo, A.: The Global Energy Balance Archive (GEBA) version 2017: a database for worldwide measured surface energy fluxes, Earth Syst. Sci. Data, 9, 601-613, https://doi.org/10.5194/essd-9-601-2017, 2017.

Wild, M., Hakuba, M. Z., Folini, D., Dörig-Ott, P., Schär, C., Kato, S., and Long, C. N.: The cloud-free global energy balance and inferred cloud radiative effects: an assessment based on direct observations and climate models, Clim. Dynam., 52, 4787-4812, https://doi.org/10.1007/s00382-018-4413-y, 2018.

Yang, S., Wang, X. L., and Wild, M.: Homogenization and Trend Analysis of the 1958-2016 In Situ Surface Solar Radiation Records in China, J. Climate, 31, 4529-4541, https://doi.org/10.1175/JCLI-D-17-0891.1, 2018.

Yang, S., Wang, X. L., and Wild, M.: Causes of Dimming and Brightening in China Inferred from Homogenized Daily ClearSky and All-Sky in situ Surface Solar Radiation Records (19582016), J. Climate, 32, 5901-5913, https://doi.org/10.1175/JCLID-18-0666.1, 2019.

Yukimoto, S., Kawai, H., Koshiro, T., Oshima, N., Yoshida, K., Urakawa, S., Tsujino, H., Deushi, M., Tanaka, T., Hosaka, M., 
Yabu, S., Yoshimura, H., Shindo, E., Mizuta, R., Obata, A., Adachi, Y., and Ishii, M.: The Meteorological Research Institute Earth System Model Version 2.0, MRI-ESM2.0: Description and Basic Evaluation of the Physical Component, J. Meteorol. Soc. Jpn., 97, 931-965, https://doi.org/10.2151/jmsj.2019-051, 2019.
Yunfeng, L., Daren, L., Xiuji, Z., Weiliang, L., and Qing, H.: Characteristics of the spatial distribution and yearly variation of aerosol optical depth over China in last 30 years, J. Geophys. Res.-Atmos., 106, 14501-14513, https://doi.org/10.1029/2001JD900030, 2001. 